\title{
DÜBLIN
}

Technological University Dublin

ARROW@TU Dublin

\section{Development of a Novel Humidity Sensor Based on a Polymer Silver Nanoparticle Composite}

\author{
Aoife Power \\ Technological University Dublin, aoife.power@tudublin.ie \\ John Cassidy \\ Technological University Dublin, john.cassidy@tudublin.ie \\ Tony Betts \\ Technological University Dublin, anthony.betts@tudublin.ie
}

Follow this and additional works at: https://arrow.tudublin.ie/scschcpscon

Part of the Chemistry Commons

\section{Recommended Citation}

Power, A.C., Cassidy,J.F. \& Betts, A.J. (2009). Development of a Novel Humidity Sensor Based on a Polymer Silver Nanoparticle Composite. ECS transactions, vol. 19,pg. 181-190. doi:10.1149/1.3118551

This Conference Paper is brought to you for free and open access by the School of Chemical and Pharmaceutical Sciences at ARROW@TU Dublin. It has been accepted for inclusion in Conference Papers by an authorized administrator of ARROW@TU Dublin. For more information, please contact arrow.admin@tudublin.ie, aisling.coyne@tudublin.ie,gerard.connolly@tudublin.ie. Funder: DIT

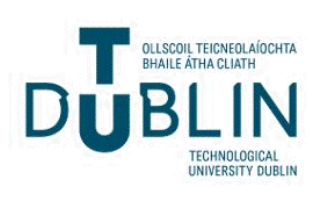




\title{
Development of Novel Humidity Sensor Based on a Polymer Silver Nanoparticle Composite.
}

\author{
A.C. Power ${ }^{a}$, J.F. Cassidy ${ }^{a}$ and A.J. Betts ${ }^{b}$ \\ ${ }^{a}$ School of Chemical and Pharmaceutical Sciences, Dublin Institute of Technology, \\ Kevin St., Dublin 8, Ireland. \\ ${ }^{\mathrm{b}}$ Directorate of Research \& Enterprise, Dublin Institute of Technology, 143-149 \\ Rathmines Rd., Dublin 6, Ireland.
}

Humidity sensing is of particular concern for many industrial applications. Humidity sensors have typically been based on a reversible interaction between a polymer and water vapour. There is work published on gas sensors based on polymer gold nanoparticle composites, where the conductivity of the composite decreases on interaction with the gas. This happens because the swelling of the polymer which increases the electron hopping distance between the gold nanoparticles.

The device in this work is a polyvinyl alcohol (PVA) silver nanoparticle composite cast on an interdigital electrode array. On application of a dc bias, a current develops which is proportional to levels of humidity from $10 \%$ to $60 \%$. The response is reversible and fast at room temperature. Details are provided of the synthesis, characterisation and use of the composite for humidity sensing. In addition the device forms the basis of a sensor for an array of gases.

\section{Introduction}

Relative Humidity (RH) detection and its control are important in a wide range of industrial applications, including the pharmaceutical, food and electronics industries. Here, close monitoring of $\mathrm{RH}$ during processes can improve product quality. Such monitoring can also be necessary during transport of materials. Therefore the development of a humidity sensing composite possessing high sensitivity, reversibility, and short response (and recovery) times is of particular benefit. Usually, RH is measured and controlled by meters that detect change in a physical property of a thin film, such as capacitance, resistivity, or thermal conductivity. These control systems require a power source, and are often relatively complex and expensive.

The key elements of a successful sensor are its selectivity, sensitivity, limit/range of detection, accuracy/reproducibility, robustness, operating conditions and cost. Nanomaterials were found to have roles in a diverse range of analytical methods particularly in sensing applications (1-5).

Increased interest in nanomaterials, especially metallic nanostructures, may be attributed to the often novel physical and chemical properties these nanoparticles display when compared to their bulk counterparts.

Polymers have been widely utilized in a wide range of sensing devices with definite roles, either in the sensing mechanism or through immobilizing the species responsible for sensing of the analyte component. This is possible as polymers may be tailored for particular properties, are easily processed, and may be selected to be inert in the environment containing the analyte. Coupling nanoparticles with specific polymers 
within nanocomposites has been shown to be very effective in producing highly selective and sensitive gas sensors (6-8). Therefore nanotechnology could have many applications in the development of future gas sensors, contributing greatly to both sensitivity and selectivity.

\begin{abstract}
Aim
The intention of this work was to prepare and characterise a novel silver nanoparticle PVA composite material, and then investigate the composite materials performance as a sensing membrane (with emphasis on the materials efficacy as a humidity sensor) when coated on an interdigital electrode array.
\end{abstract}

\title{
Experimental
}

\section{$\underline{\text { Materials }}$}

Silver nitrate (purum p.a. $\geq 99.0 \%$ ), sodium borohydride (reagent Plus 99\%) polyvinyl alcohol (PVA), (99+\% hydrolyzed, typical M.W. 89000-98000 gmol $^{-1}$ ), cyclohexane (anhydrous, 99.5\%), and methanol (anhydrous 99.8\%) were all purchased from Sigma Aldrich and used as received without further purification. The corundum ceramic based substrates with platinum interdigital electrodes (CC2.W2), or graphite interdigital electrodes (CC1.W4), were purchased from BVT Technologies and used as received.

\section{$\underline{\text { Instrumentation }}$}

The following instrumentation was used during the course of the study;

- Perkin Elmer, Lambda 900 Spectrometer.

- Malvern, nano series Zetasizer.

- JEOL, 100CX Transmission Electron Microscope.

- PICO, ADC 16 high resolution data logger.

o Thompson Electro Chem Ltd., Ministat Precision Potentiostat.

- Electro-Tech systems, controlled environment chamber with humidity control system, model 503-20.

\section{Preparation of PVA capped Ag Nanoparticles}

PVA capped silver colloids were prepared chemically, by reduction with sodium borohydride, producing a colloidal dispersion with a Ag to PVA monomer, weight ratio of approximately 1:1. The resulting colloids were then characterised by a combination of UV-Vis Spectroscopy (UV-Vis), dynamic light scattering (DLS) and Transmission electron microscopy (TEM). (9)

\section{Preparation of Nanocomposite Film}

The colloid polymer composites were applied to interdigital electrodes in the form of coatings. A set volume of the colloid was deposited by drop coating to the surface of the substrates electrodes and air dried over a period of $12-15$ hours. 
Ag PVA nano composite coatings were applied to interdigital electrodes as described earlier. A dc voltage of $1 \mathrm{~V}$ was then applied across the interdigital electrode using a Thompson ministat potentiostat and the resulting signal response measured. The sensors response is a voltage signal which is produced by the $1 \mathrm{k} \Omega$ 'counter' resistor with the interdigital electrode array. The sensing membrane's responses to selected vapours were collected using a high resolution data logger (PICO ADC 16).

All experiments were conducted at room temperature $\left(20 \pm 2^{\circ} \mathrm{C}\right.$ ) and $\mathrm{N}_{2}$ (Oxygen Free $99.998 \%$, BOC Gases) was used as the reference gas. The vapour streams were produced by bubbling dry $\mathrm{N}_{2}$ gas through a bubbler of the (particular vapour) solvent.

When exposed to water which has a dielectric constant of 80.2 at $20^{\circ} \mathrm{C},(10 \mathrm{a})$ and non polar (e.g. cyclohexane, with a dielectric constant of 2.0243 at $20^{\circ} \mathrm{C}(10 \mathrm{~b})$ ) vapour streams, a response was only observed for the water vapour. The sensitivity of the film's response to water vapour and thus suitability as a humidity sensor was further investigated by exposure of the sensor to a series of known humidity levels. A controlled environment chamber with humidity control system (Electro-Tech systems model 50320) was used to set each humidity level. The relative humidity within the chamber was maintained at a set level in the range of $5-100 \% \mathrm{RH}$ with an accuracy of $\pm 1 \% \mathrm{RH}$. In addition the temperature of the environment was kept constant at $21.3 \pm 0.1{ }^{\circ} \mathrm{C}$.

\section{Results/Discussion}

\section{Colloid Characterisation}

UV-Vis Analysis. The absorption spectrum of the colloid, figure 1 indicates the production of the nanoparticles where the presence of a plasmon absorption band at $\sim 400$ $\mathrm{nm}$ is characteristic of silver nanoparticles (11). 


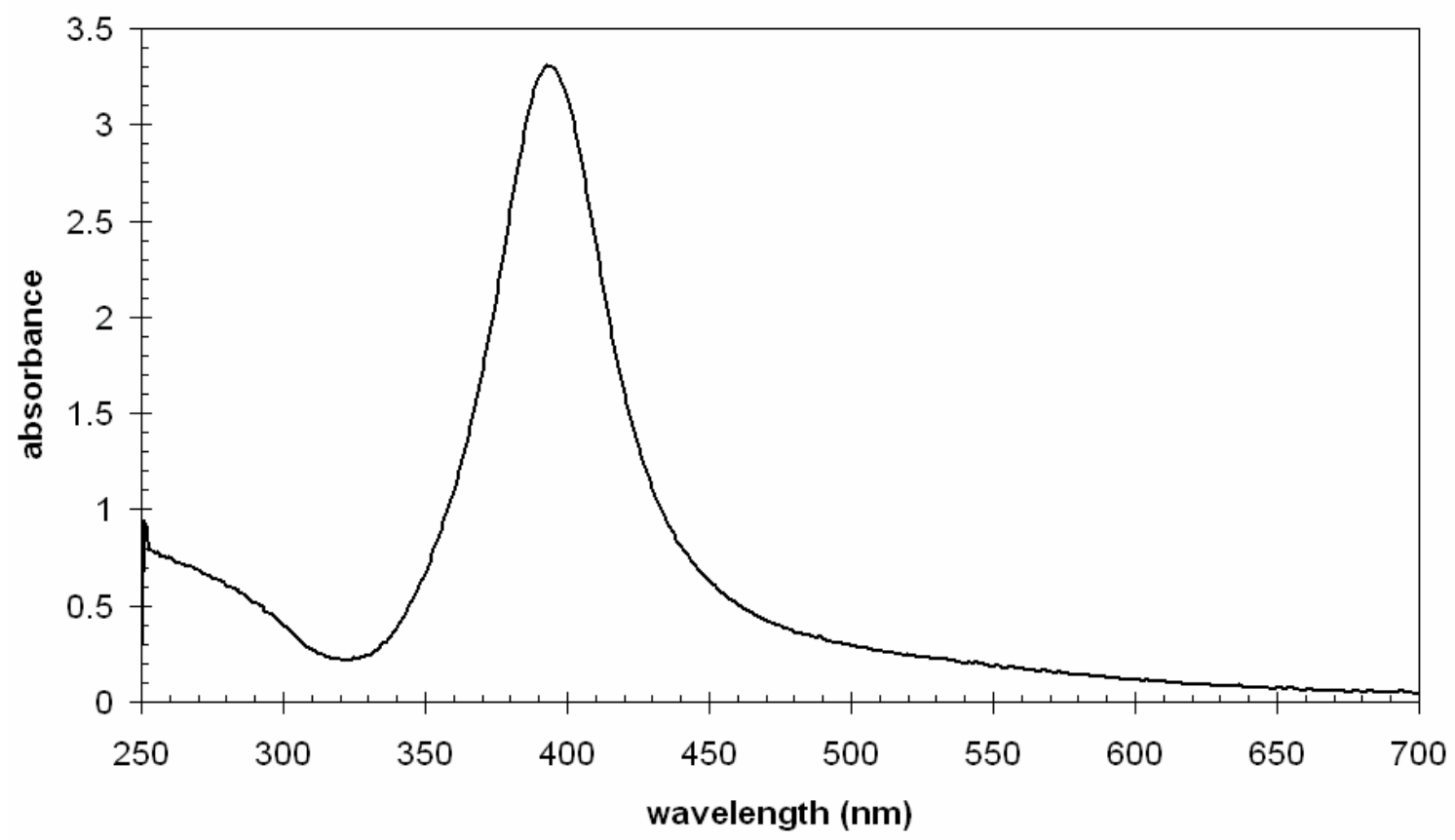

Figure 1. UV-Vis spectrum of colloidal polymer composite dispersion, with $\lambda$ max of 391 $\mathrm{nm}$. Particles were stable and the absorption was Gaussian. $\left[\mathrm{Ag}^{+}\right]=0.05$ moles, $[\mathrm{PVA}]=$ $7.06 \times 10^{-8}$ moles, $\left[\mathrm{NaBH}_{4}\right]=0.06$ moles, Solvent $=$ water.

Such plasmon bands are a result of the unique physical properties of the nanoparticles themselves. When an external electro-magnetic field such as light is applied to a metal, the conduction electrons move collectively so as to screen the perturbed charge distribution, in what is known as plasma oscillation. The surface plasmon resonance (SPR) is therefore, a collective excitation mode of the plasma localized near the metal surface. In the case of a metal nanoparticle, the surface plasmon mode is 'restricted' due to the small dimensions to which the electrons are confined, i.e. the surface plasmon mode must conform to the boundaries of the dimensions of the nanoparticle (12).

Dynamic light scattering. Size analysis by DLS confirmed that a colloidal dispersion was produced with particles ranging in size between about $8 \mathrm{~nm}-38 \mathrm{~nm}$. The approximate breakdown of the nanoparticles diameters were as follows, $26.5 \% 13-14 \mathrm{~nm}, 21.5 \% 11$ $12 \mathrm{~nm}, 20 \% 15-17 \mathrm{~nm}, 12 \% 17-19 \mathrm{~nm}, 9 \% 8-11 \mathrm{~nm}, 5 \% 19-21 \mathrm{~nm}, 2.5 \% 21-25 \mathrm{~nm}$, $3.5 \% 25-38 \mathrm{~nm}$, resulting in the average particle diameter range of $21-22 \mathrm{~nm}$. 


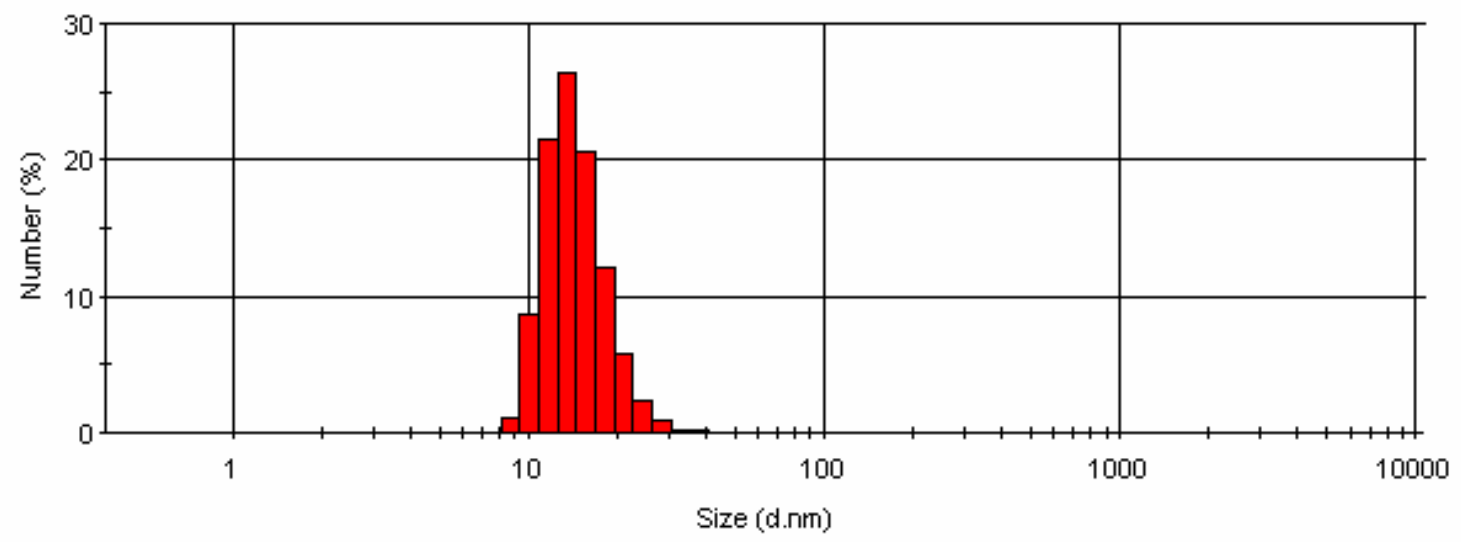

Figure 2. Distribution of particle diameters within the Ag PVA colloid determined by DLS. The sample analysised was prepared in an identical manner to that in figure 1.

Transmission electron microscopy. Using TEM an image of the nanoparticles, (figure 3), was obtained by the interaction of the coating and the beam of electrons transmitted through the coating. Before analysis the original colloidal sample was diluted in methanol and sonicated for 30 mins, before being cast onto the TEM grid (Agar scientific, formvar/carbon 200 mesh $(\mathrm{Cu})$ ) by drop coating. The average diameter of the nanoparticles in figure 3 was determined to be in the range of $21-22 \mathrm{~nm}$, using ImageJ software (13), which correlates well with the DLS result.

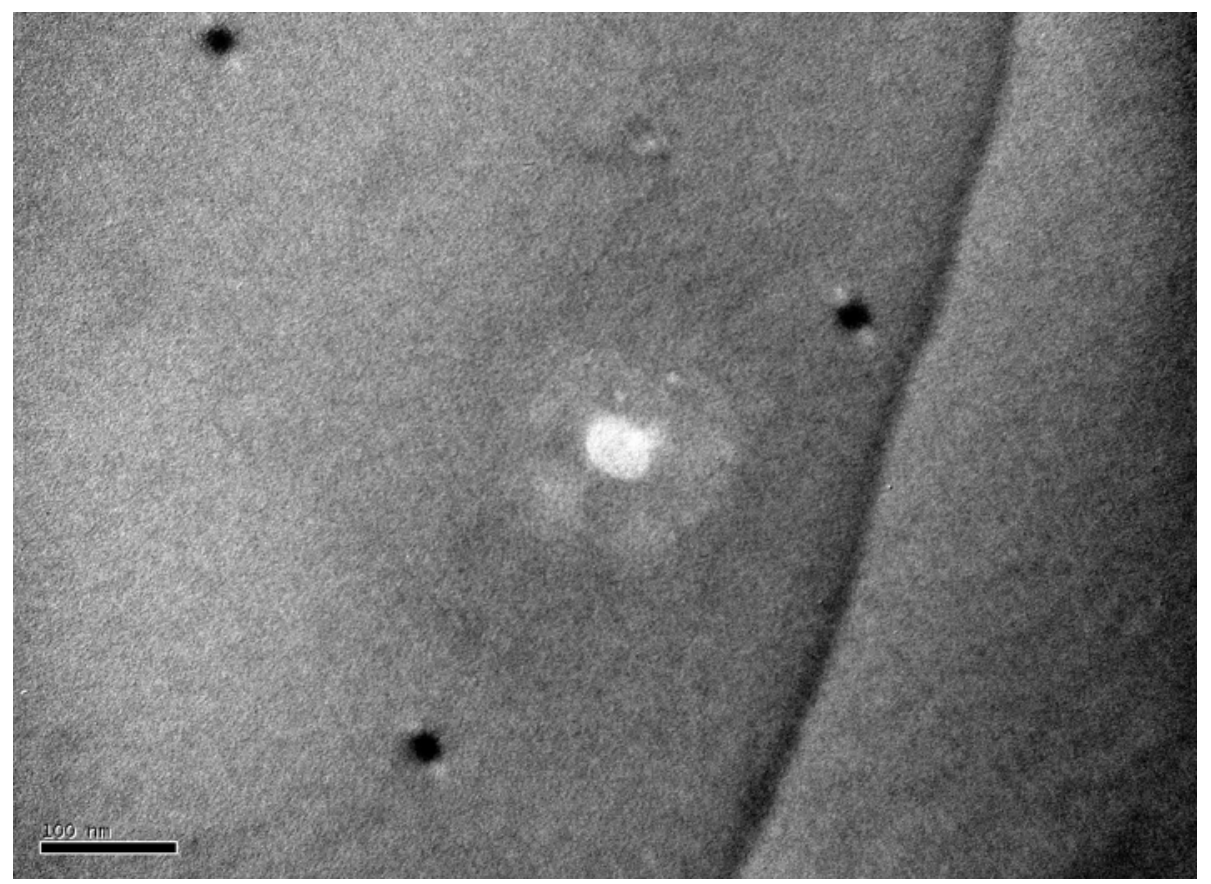

Figure 3. TEM image of silver nanoparticles stabilised with PVA. Colloidal dispersion was prepared as in figure 1 and then diluted by a factor of 10 with methanol. The average diameter of nanoparticles were $21-22 \mathrm{~nm}$, was determined using imageJ. Note; bar legend in image is $100 \mathrm{~nm}$. 
A clear response was observed when the coated substrates were exposed to breath. This response was found to be both rapid and repeatable over time. It was determined experimentally that this response was due to the presence of water vapour in an exhalation. Figure 4 shows the response of repeated exposure to breath at regular time intervals; response is immediate, with a relatively consistent max peak height, with a total response time (despite a slight lag in the decay of the response signal) observed of 5-10 seconds.

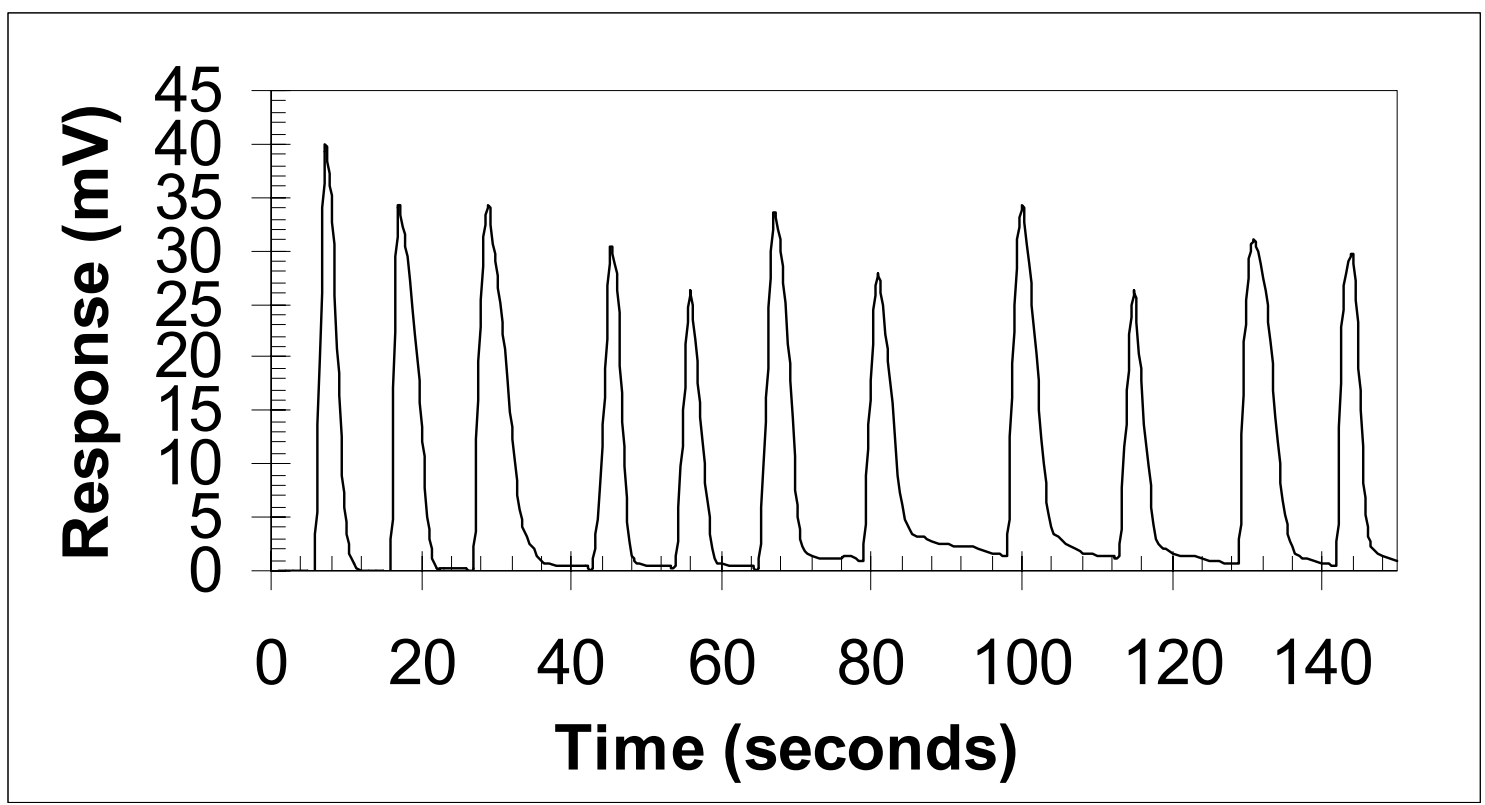

Figure 4. Plot of sensors response to a change in environment. The sensing membrane was repeatedly exposed to breath (exhalations) at regular time intervals.

\section{$\underline{\text { Response of coating to water and other vapours }}$}

Early results indicated that the coatings possessed a relatively good selectivity as a humidity detector. Vapour streams were produced by bubbling $\mathrm{N}_{2}$ through the appropriate solvent contained in an insulated Drechsel flask (in order to maintain a constant temperature and thus vapour pressure / concentration). A clear response for water vapour was observed, with no obvious response for other non polar vapours, such as cyclohexane.

In figure 5, the sensing coating was again exposed repeatedly to water vapour using the 'bubbler' apparatus. The level of response was again observed to be relatively consistent. The response signal was higher then that observed in figure 4 and again immediate initially, within the first 10-20 seconds, before 'slowing' to a steady state of signal was observed. This resulted in a lag in the signal which was found to be proportional to $\mathrm{t}^{1 / 2}$ suggesting the signal response was diffusion controlled. In figure 5 it can also be seen that there is an early breaking in before there is a steady state interaction with the water vapour. 


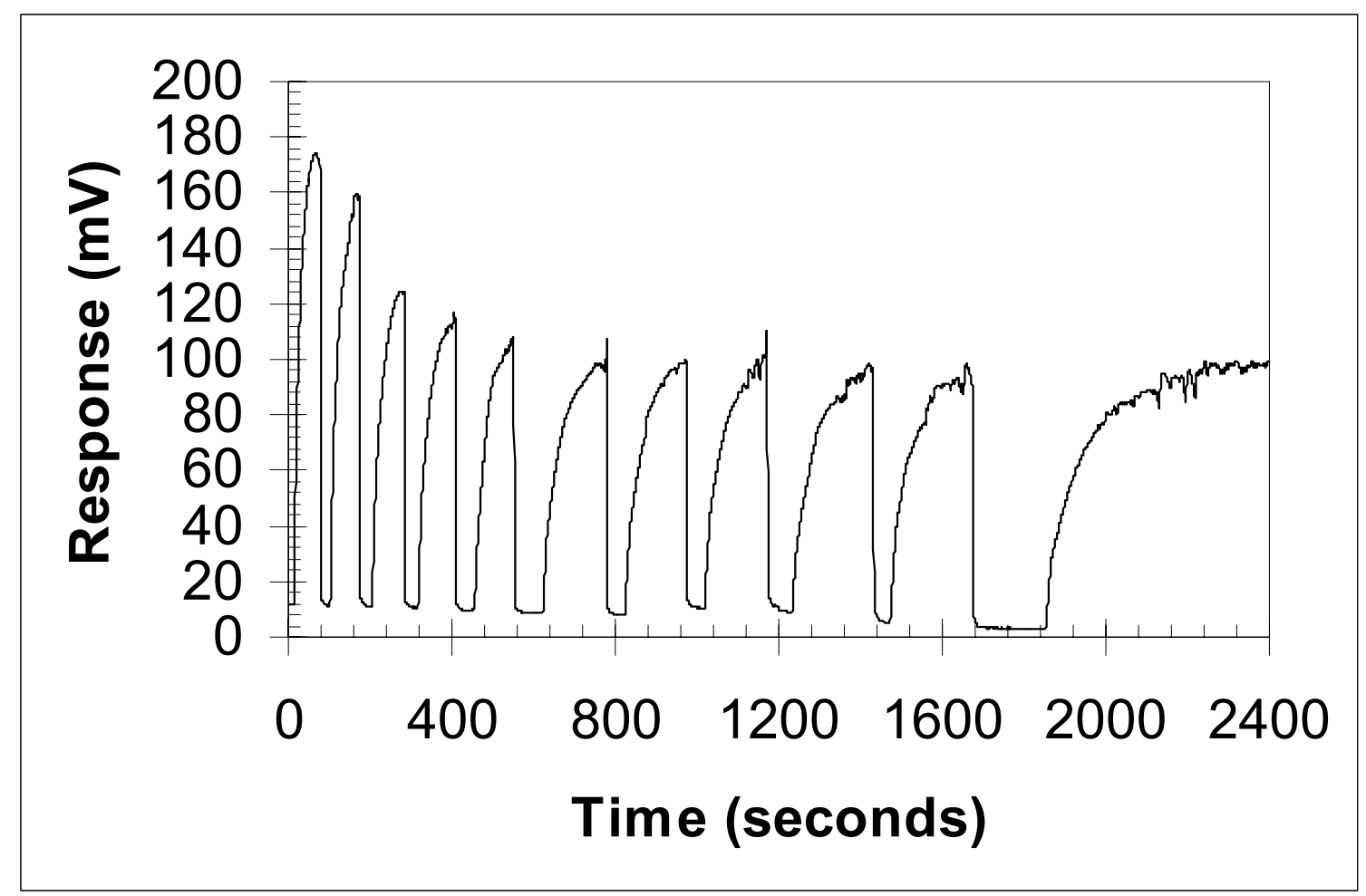

Figure 5. Sensors response to repeated water vapour exposure. Exposure was conducted using the bubbler apparatus, where the streams passing over the sensing membrane were 'switched' from the reference gas and water vapour at increasing time intervals.

In both the preceding and following experiments the sensors response is a constant current in $\mu \mathrm{A}$, which the $1 \mathrm{k} \Omega$ counter resistor produces from the $1 \mathrm{~V}$ dc voltage was applied across the coated interdigital array.

\section{$\underline{\text { Humidity investigation }}$}

The coated interdigital electrode was placed in a precisely controlled environment chamber, with a humidity control system, here the sensors response to increasing \% RH at a constant temperature of $21.3 \pm 0.1^{\circ} \mathrm{C}$ was found to be constant and relatively linear over the $10-60 \%$ RH range. Before each measurement the sensor was 'powered off', i.e. no voltage was applied across it and the environment set to the \% $\mathrm{RH}$ of interest, the environment was allowed to equilibrate for 15 mins, before each reading. Figure 6 shows the steady state response obtained in this analysis, in this case the humidity levels being measured were already constant before 'sensing' occurred, resulting in a response with none of the ramping up or down seen previously in figures $4 \& 5$ were the 'humidity' levels was adjusted during the measurement. 


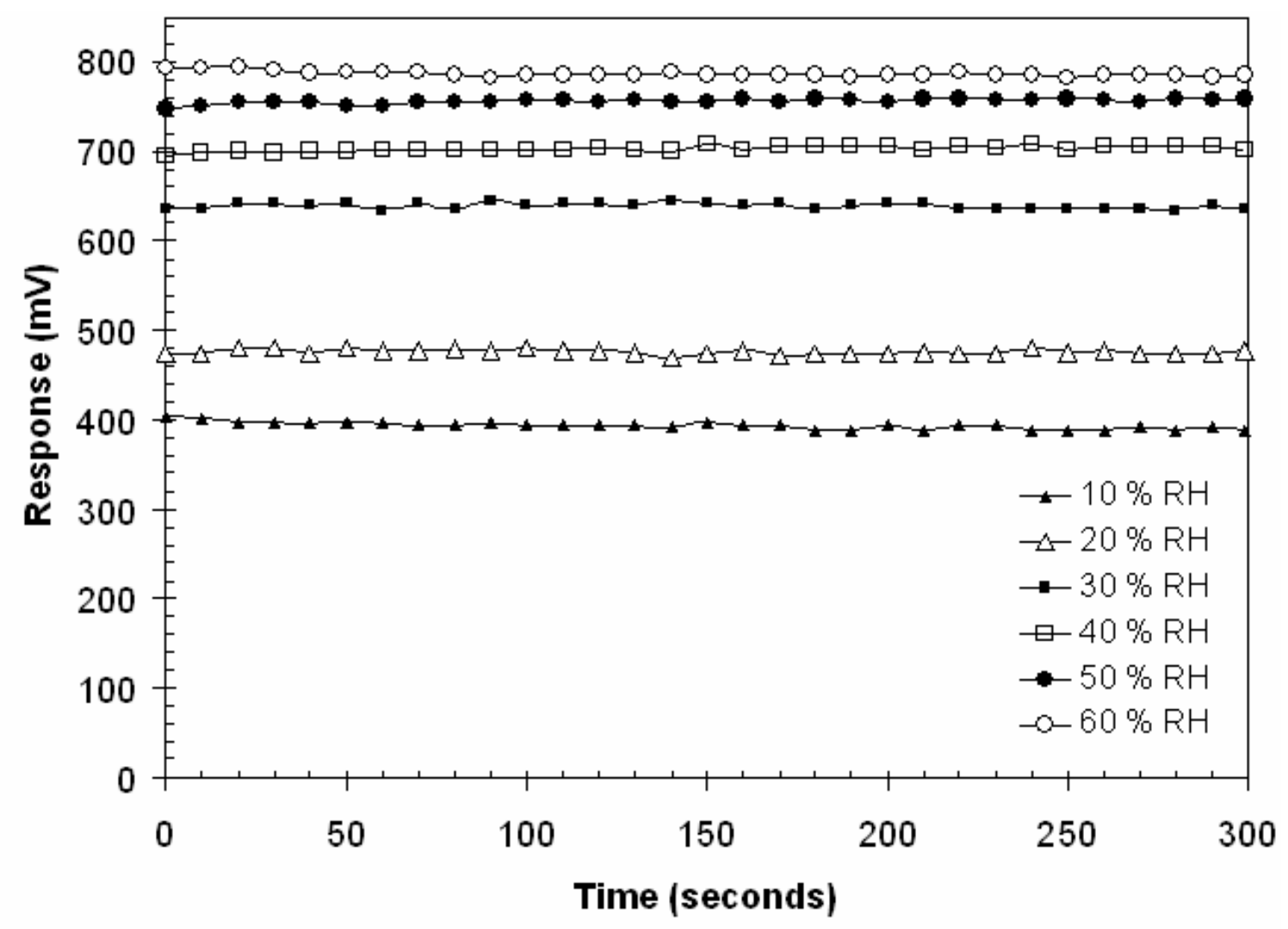

Figure 6. Graphical representation of sensors response to increasing \% RH over time.

Typical results for repeated exposures of the same film (exposed repeatedly to set $\%$ RH humidities in the $10-60 \%$ RH range) are summarised in figure 7 . We theorise that the mechanism of the sensing layer in this study may involve the presence of electrolyte remaining from the synthesis embedded in the polymer. Introduction of water vapour allows hydration of the electrolyte increasing its mobility which allows an increase in current. Further investigation of the role of "electrolyte" in the layer was conducted; when a similar composite of the same ionic strength was prepared (using $\mathrm{KNO}_{3}$ instead of $\mathrm{AgNO}_{3}$ ) it yielded no response under the same experimental conditions. This suggests that migration is assisted by the silver nanoparticles. 


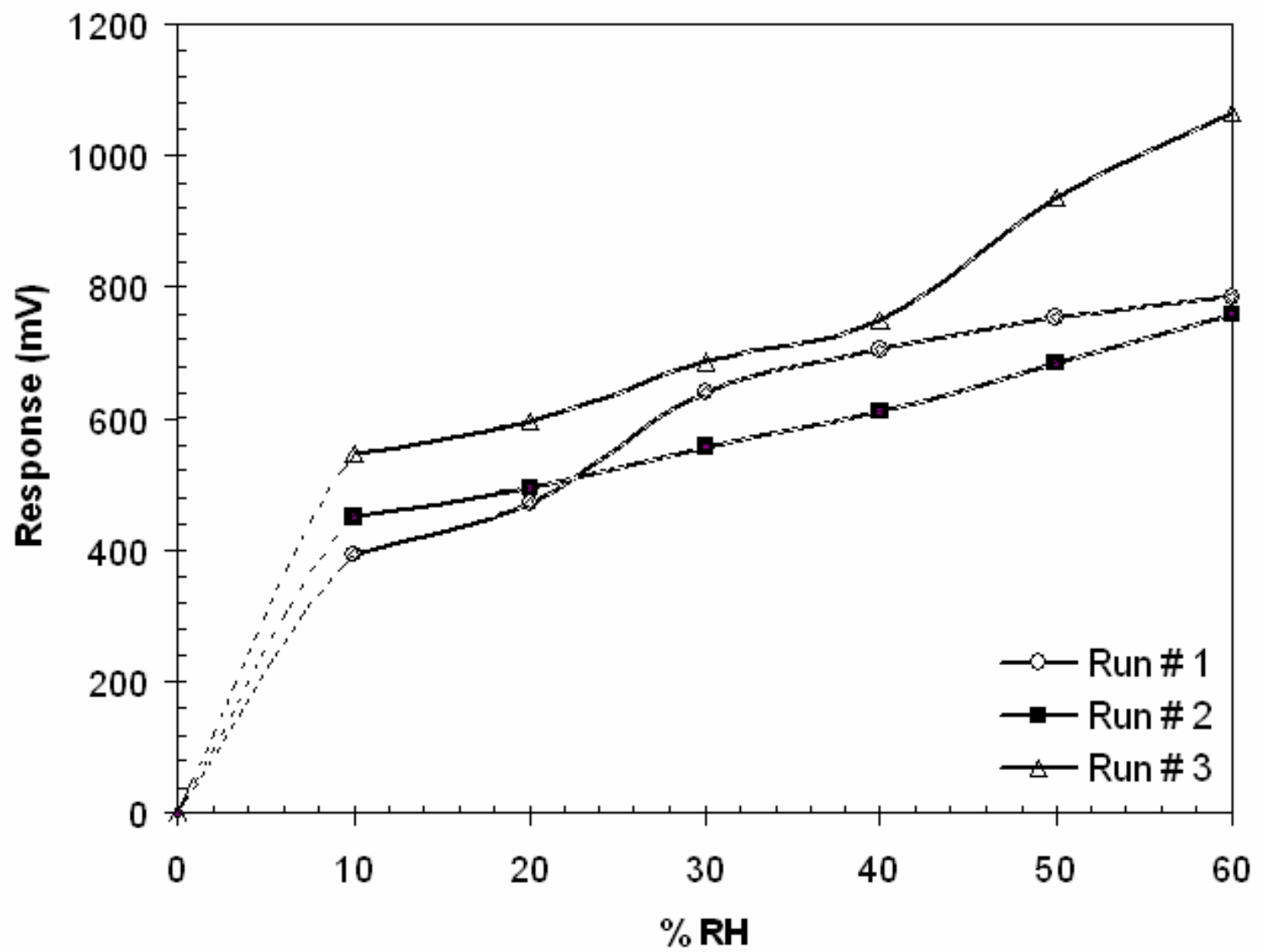

Figure 7. The sensors response to repeated exposures to varying \% $\mathrm{RH}$ at set time intervals. A level of repeatability exists, however hysteresis in the humidity response was observed. This may be attributed to the hygroscopic nature of PVA.

It should be noted if the values of the responses for each \% RH in Figure 6 were plotted the resulting line would be relatively linear however it would produce a nonzero intercept as prior analysis indicated (see figures $4 \& 5$ ) that at $0 \% \mathrm{RH}$ no response occurred, the sensors response between the lower humidities $0-10 \%$ RH was estimated, and indicated in figure 7, by a broken line. This theorised response suggests a dramatic increase in the level of response at lower humidities followed by a gradual levelling off of the response observed, as the level of humidity continues to increase, this effect was illustrated somewhat in figure 5, where a slight lag (seconds), in response time was observed.

\section{Conclusions}

PVA capped silver nanoparticles $(8 \mathrm{~nm}-38 \mathrm{~nm})$ were prepared chemically by reduction to produce a poly vinyl alcohol silver nanoparticle composite. This composite when cast on an interdigital electrode array and on application of a dc bias, was observed to produce a current, which is proportional to levels of humidity from $10 \% \mathrm{RH}$ to $60 \% \mathrm{RH}$. The sensor gave a reversible, rapid response at STP. The steady state response was selective and relatively linear with increasing concentrations. Hysteresis of the layer on repeated extended exposures indicates the need of a reset method. Layer thickness is also not yet well defined, which infringes on the consistency of results for each new layer thus more work is required to optimise the thickness of the coating. 
The sensors selectivity is biased in favour of water, a polar solvent, to non polar solvents (e.g. cyclohexane). Further investigation of the sensors response to other polar solvents would be necessary to gauge its true selectivity. Also the stoichiometry of the reduction by $\mathrm{NaBH}_{4}$ is itself difficult. Further investigation of the polyelectrolyte theory is necessary, thus, an impedance study of the layer could be useful.

\section{Acknowledgments}

A.C. Power thanks the ABBEST PhD Scholarship Programme of the Dublin Institute of Technology, and A. Casey, J. Dorney, E. Ginty, I. Naydenova and E. Ryan for their assistance during the experimental process.

\section{References}

1. Li Han et al., Sensors and Actuators B-Chemical, 106, 431-441 (2005)

2. Xiliang Luo et al., Electroanalysis, 18, 319-326 (2006)

3. Naydenova I, et al., Applied Physics Letters, 92, 031109 (2008)

4. C. Drake et al., International Materials Reviews, 52, 289-317 (2007)

5. Katz E, et al., Electroanalysis, 16, 19-44 (2004)

6. Li Y, et al., Talanta, 62, 707-712 (2004)

7. Walcarius A, et al., Journal of Materials Chemistry, 15, 3663-3689 (2005)

8. B. Adhikari \& S. Majumdar, Progress in Polymer Science, 29, 699-766 (2004)

9. Libor Kvitek et al., Journal of Materials Chemistry, 15, 1099-1105 (2005)

10. David R. Lide, Editor in chief, CRC handbook of chemistry and physics, 89th ed., Boca Raton, Fla, CRC; London, Taylor \& Francis, a; 6-163, b; 6-4 (2008)

11. Taihua Li et al., Materials Chemistry and Physics, 105, 325-330 (2007)

12. Kelly KL, et al., Journal of Physical Chemistry B, 107, 668-677 (2003)

13. http://rsb.info.nih.gov/ij/ (Feb 2009) 